\title{
Optimization of Human Resources: Does Human Resource Pooling in an Organization Help in Improving Capacity Building and Efficiency? A Case Study
}

\author{
Mruthyanjaya Rao Mangipudi1 ${ }^{*}$, Kanaka Durga Veera Prasad1*\#, Rajesh Vaidya² \\ ${ }^{1}$ Department of Management Studies, RTM Nagpur University, Nagpur, India \\ ${ }^{2}$ Department of Management Technology, Shri Ramdeobaba College of Engineering \& Management, Nagpur, India \\ Email: "prasadkanaka2003@yahoo.coin
}

How to cite this paper: Mangipudi, M.R., Prasad, K.D.V. and Vaidya, R. (2019) Optimization of Human Resources: Does Human Resource Pooling in an Organization Help in Improving Capacity Building and Efficiency? A Case Study. Journal of Human Resource and Sustainability Studies, 7, 397-405.

https://doi.org/10.4236/jhrss.2019.73026

Received: July 19, 2019

Accepted: August 30, 2019

Published: September 2, 2019

Copyright $\odot 2019$ by author(s) and Scientific Research Publishing Inc. This work is licensed under the Creative Commons Attribution International License (CC BY 4.0).

http://creativecommons.org/licenses/by/4.0/

\begin{abstract}
The human resource pooling is assembling or grouping of human resources for optimal use of human resources to reduce the cost and improve efficiency. The human resource pooling can happen on structural changes, merging and clustering, alteration of existing business processes and policies in accordance with the new pool combination. With the resource pooling, one can avoid additional staff training due to attrition and recruitment costs which are costly and time-consuming activity in finding suitable replacements. Migration into the new system creates certain cultural gaps and this gap further increases even while adapting to new technology. Resource pooling reduces the employees slack or waiting time in the process and motivates the employees for team work. In this research case study, the authors report the effect and results of resource pooling in an IT conglomerate where significant cost savings and improvement in the efficiency of the people in functions like finance, human resources, administration and other related departments are realized.
\end{abstract}

\section{Keywords}

Resource Pooling, Migration, Structural Changes, Employee, Efficiency

\section{Introduction}

Resource Pooling can be described as grouping of resources, assets, machinery and numbers, finances, ways and means, data, persons, vehicles etc., to derive ${ }^{\star}$ Both authors equally contributed. 
maximum benefit out of the pool that is combined, joined and gathered than what each of them achieves individually. Resource pooling helps in maximizing advantage or minimizing risk. Thus, Human Resources Pooling can be defined as "an activity that combines and ensures a perfect mix of different people from various backgrounds having diversified skill sets to derive the maximum or optimum productivity of a given task".

Resource Pooling is considered to be the innovative and cost-effective way of handling resources. Budget and financial constraints and restraints force the top level management to find innovative and cost-effective ways to deliver the services and their programs. Further, significant savings can be realized through innovative ways, which will be helpful to deliver the support functions at minimal cost [1].

Resource pooling is a combination of different people with an opportunity to bring every quality that it brings to the table. There would be different backgrounds of people who represent different cultures, speak various languages, practices different customs etc., which are essential for any work place to ensure overarching system. Resource pooling also presents the organization, a combined effort with diversified skill sets. It actually disrupts the existing monotony in any organization that suffers lack of creativity. The resource pool is a group of individuals who can take new challenges that include a pool of talent from diverse backgrounds, multi-skills and varied experiences. This group consists of full time employers, part timers and even freelancers [2].

Resource pool provides a mechanism to organize supply of resources in a meaningful way to support human resource planning and can be grouped in such a way to optimize the operations. Resource pooling can be done to suit the organizational needs taking the assistance of Human Resource Department. However, pooling and categorization of resources can vary from organization to organization, and pools are static and new pools can be added in some cases. The staffing workbench also a type of resource pooling and can be placeholders for future capacity [3].

The Department of Information and Communication Technology, Philippines to overcome the need of skilled manpower created partnerships with colleges (SUCs-strategic unit colleges) where the students will do the research and develop applications with the student's research aligned with DICT projects (DICT, Republic of the Philippines, 2018) [4]. Researchers John Quelch and Helen Bloom (2015) suggested on creating an effective global work force means knowing when to use "expats", when to hire "locals" and how to create that new class of employees-the "glopats" in their strategic paper Ten Steps to a Global Human Resources Strategy to overcome the demand of skilled manager [5].

The authors critically reviewed the research and empirical studies available on the subject resource pooling but could find only a limited research in this area. This present study was carried an IT conglomerate at Hyderabad but the described pooling can be applied to the similar industries of the other areas with minimal modifications based on the organizations structure and business. 


\section{Why Resource Polling?}

During the research, it is found that resource pooling seems to have been required by an organization to meet the business demands of the present and past. It is not possible to maintain the exact balance of the staff and their expertise because of volatile business changes on regular basis. The resource pooling can give stability and scalability, reduce the costs, and effectively the services would be delivered. The resource pooling also simplifies on boarding employees trained in more than one department and reduce the delivery delays, saving the recruitment costs. The employees will be more engaged and provide a competitive edge with resource pooling.

\section{Review of Literature}

Resource pooling is not without any cost. The reporting mechanisms and structure will be difficult in the initial period and will resisted by some employees reducing the performance temporarily, however it is better opportunity to make better use of available resources [6].

The resource pooling remains an important mechanism to the organizations not only for just financial benefits but also to better manage their human resources and improve service quality.

However, to realize the maximum benefits from the resource pooling, that pools must be actively managed and not just left to run themselves. Francis Coleman and Gerry Winters [7] developed a strategy to visualize greater flexibility and availability of tools/information from the pooling networks to assist the human resource pooling. Msiska [8], identified the occurrences of staff pooling during the implementation and reconfiguration of the DHIS2 health information software platform in Malawi and assessed the efficacy, challenges and factors for staff pooling as a strategy to mitigate human resource challenges in developing countries. The resource pooling also can be helpful in "How to Increase the Diversity, Equity, and Inclusiveness in recruitment.

Talent Pooling is not an exact science, it is best approached on a business-by-business and role-by-role basis; flexibility is vital [9]. However, resource pooling can make assumptions on how to recruit an identified number of specific roles but a wider appreciation. In big enterprises the pooling of interest accounting is the preferred method of valuing the combined company, resulting in a larger EPS. However, pooling of interests accounting will not be allowed under certain circumstances relating to stock options and change-in-control agreements, among other areas of HR responsibility. In order to prepare for business combinations, benefits professionals need to review their plans and create a list of revisions that will ensure that the use of pooling of interests accounting will not be precluded their organization's future planning and the potential costs incurred are critical [10]. Activity of pooling may be done by combining some categories of people working under different departments, wings, units, locations and at different levels. 


\section{Structure of the Manuscript}

The article is organized as follows:

This manuscript is structured into three sections in Section (4) the theoretical framework was discussed based on the available literature. In second section (Section 5) the six areas where the resource pooling is possible is emphasized in detail. We listed out the six departments where pooling is possible and developed framework to pool the resources for the benefit of the organization. We have also considered the present organization structure (Figure 1) and modified the organization structure (Figure 2) with the appropriate units/department that are being pooled.

\section{Theoretical Framework}

Boon et al. 2018 [11] observed Human capital is an important construct in a variety of fields spanning from micro scholarship in psychology to macro scholarship in economics. The researchers focused on integrating two streams of research which focus directly on human capital, but have approached human capital in different ways: strategic human capital (SHC), and strategic HRM. Faith Wanjira Muriithi et al. [12] critically reviewed the studies conducted on the subject, identifying empirical and contextual gaps that exist in the literature subject,

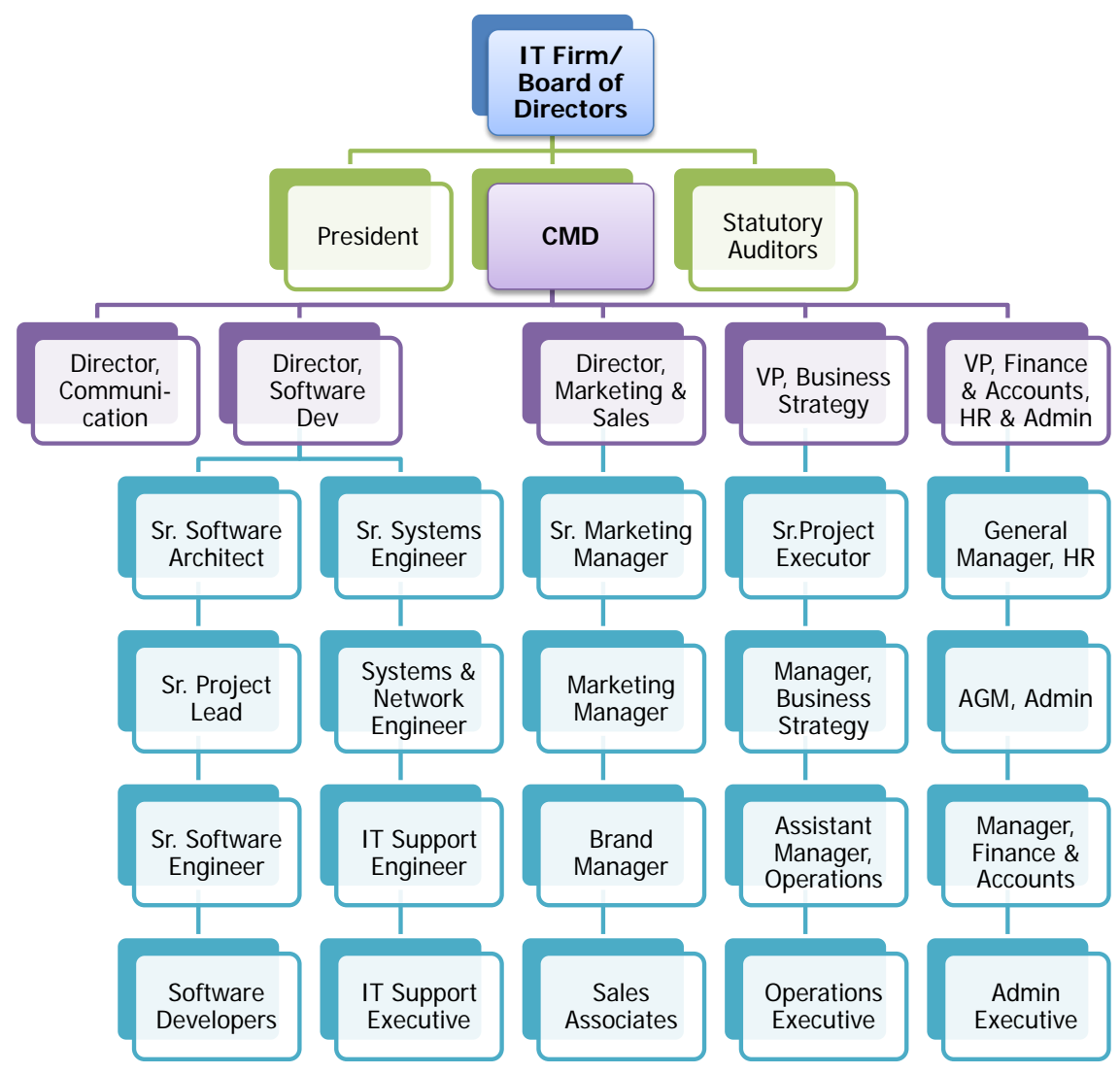

Figure 1. Organization Hierarchy (Present)-Hierarchical type structure. Source: A general organizational schema of IT industry, NASSCOM, 2018. 


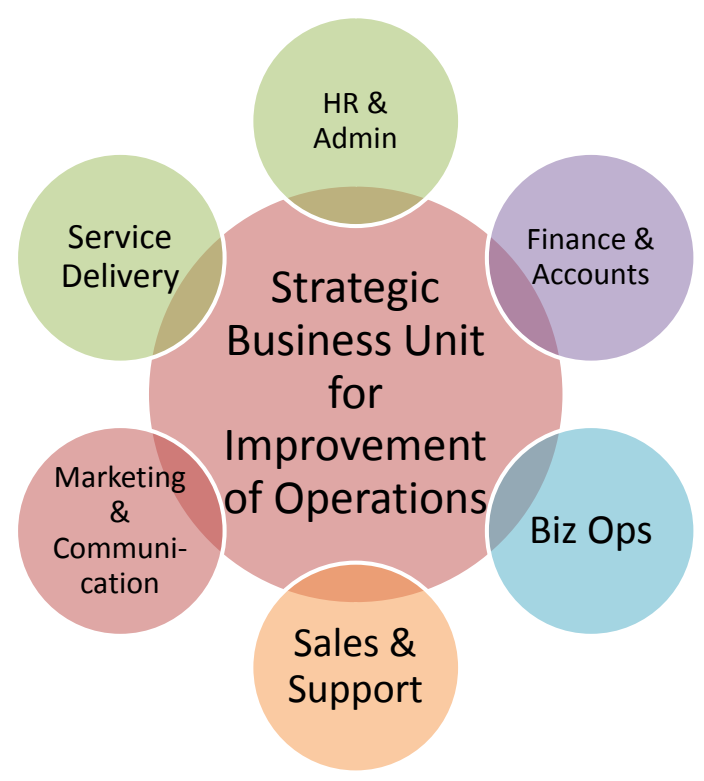

Figure 2. Proposed new structure with resource pooling. The SBUIO shows both overlapping relationships and the relationship of a central idea in a cycle. Every function outside corresponds and combined to make the unit efficient and multi-tasking unit. Source: Developed by the authors-Primary Data.

and proposing a conceptual framework on the subjects. The authors further suggested including other variables which may include the organization strategies, its structures and policies, the leadership styles and beliefs and others that might be of help to explain the relationships extensively. Keith McIntosh et al. [13] studied the expanding the Recruitment Pool in human resource pooling through increasing diversity, equity, and inclusion to increase the organizational efficiency. Based on the above limited research and models, the researchers have developed the theoretical framework and identified the following can be areas that can be grouped and assigned multiple tasks:

\section{Possibility of Resource Pooling}

It is observed during the study that there are various functions that are being carried out under different departments, locations, units that give us an understanding that there exists some similarity amongst them. If these functions are combined together and bringing a couple of functions under the ambit of one or two functions, the productivity may be reached to its highest level.

1) Service Delivery: In this, Project Leads, Project Executives, Project Managers, Project Directors, Manager, Service Delivery. Their job is to ensure that the project is delivered on time without any deviation from the scope of work that they agreed.

2) Business Operations: Manager-Operations, Chief Operating Officer, Executive Operations. These people ensure that there is no glitch in the operations that they conduct during delivery of the service and also during deployment of service or product. 
3) Sales \& Support: Pre Sales, Post Sales, Support Services Engineer, Implementation Engineer, Technical Support Executive etc. These members would extend the service starting from participating in the tender till finalization of the deal and release of mandate to the firm which undertakes to execute the work or project.

4) Marketing \& Communication: Branding Manager, Marketing Manager, Marketing Executive, VP-Marketing, Director-Marketing. These members ensure that the services or products are marketed across various geographical locations explaining the benefits of such service and product thereby increasing the visibility of the product or service.

5) HR \& Admin: The members in this unit range from Recruiters, Payroll Execution, Compensation and Benefit Planners, HR Business Partners, HR Shared Services, Sales HR, Employee Relations, Performance Evaluators, Employee Engagement People, Employee Communications, Employee Reimbursements etc.

6) Finance \& Accounts: Payroll Executives, Attendance Tracking, Bills Scrutinizers, Banking Executives, Cost Accountants, Finance Manager etc.

From Figure 1, a hierarchical structure type hierarchy, it can be observed that the present Strategic Business Unit headed by CMD of the unit and with respective Directors like Communication, Software Development reporting to CMD. Further to the next level Software Architects, System Engineers, Marketing Manager, Operations Managers, Administration Managers reporting to their immediate higher level, and so on Marketing and Sales, Business Strategy, VP, Finance and Accounts, $\mathrm{HR}$ and Administrations Project Directors, Managers and Chief Managers. The SBU has functions of Sales Support, Marketing and Service Delivery, HR \& Administration, Finance and Accounts and Business Operations. The structure was further divided each function consisting of Leads, Executives, other staff and support staff assisting each functions. The SBU has also other functions like Software development, Testing, Data Analytics, Integration, and Other Units (not shown in Figure 1). The present hierarchical type structure with too many levels is difficult to handle and all the staff carrying out the common functions are working separately in each functional area. The present structure (Figure 1) has several levels and each of the units functioning separately with the group resources i.e. staff. From the structure it can be further observed that there several members of staff performing common assignments across the functional groups. From the present structure there is every possibility of slack time of employees and under-utilization of human resources. Therefore, resource pooling was planned with new structure as indicated in Figure 2.

\subsection{How to Create Resource Pooling?}

The authors have considered carefully at each function, and the human resources (staff) therein the departments/units. The researchers have identified that some of the positions, functions and the departments can be grouped based on the common assignments the staff carry out. This is to minimize the moni- 
toring and maximizing the efficiency of the new unit that would be formed and/or for the existing unit where the resources are in short supply. For example, the staff members who carry out common assignments of HR payroll \& Admin \& Finance function are combined to the extent possible as far as salary processing and attendance tracking and bills scrutiny etc.

\section{Important Note}

Before pooling the resources, a survey of the employee and their interest to join the team was carried out and based on the employee interests the resources were pooled and distributed to the functions accordingly. The human resources were grouped to total six functions as indicated in Figure 2.

The new proposed structure where the resources from the respective six functions as indicated in the figure who is having common assignments have been pooled and brought under one reporting level SBIO Head. The employees will be moved between teams depending on the demand with one primary and secondary team leads.

This new proposed structure enabled sharing of responsibilities amongst similar assignments among the functions, which will eventually have resulted the organization financially healthier, because it reduces the costs involved in maintaining different departments and different persons for each function. Further, the proposed structure has only one level of supervision, and lesser the monitoring, the higher the productivity and efficiency for the leader. In the long run, every individual would be able to handle the other functions, as under resource pooling, every employee will be given multi-tasking assignments. The organization can withstand even when there is high attrition. It eases the stress as there is always other person to handle his/her assignment during interim absenteeism, like maternity leave, sick leave periods etc. There will be any gaps or any there could be no vacuum created because of leaving the organization by some employees. It gives the organization some breathing time to fill the gap in.

\subsection{Benefits of the Proposed Structure}

- Employee will have less slack time;

- Efficient use of available resources with cost and time efficiency;

- As the staff being moved in across the teams, the staff with common assignments will be trained in all the functions across the team;

- Redeployment of the staff is easy.

With the presence of Resource Pooling, there exists a sustainable way of doing the business. It becomes more viable when the company faces financial crunch, as it can always depend on the resource pooling that it creates to carry out the tasks with minimum or no disruption at workplace.

\subsection{Quantification of the Benefits}

We present the following a brief note the savings to the organization by application of developed resource pooling (Table 1). 
Table 1. Positive effect of primary application of the developed resource pooling strategies (only person years (PYs) saved presented at this stage).

\begin{tabular}{cc}
\hline Pre-Resource Pooling & Post-Resource Pooling \\
\hline $\begin{array}{c}\text { Office Secretaries (6 Person Years) } \\
\text { (each 1 for one department) }\end{array}$ & $\begin{array}{c}\text { Office Secretaries (3 Personal Years) } \\
\text { (for all the six departments) }\end{array}$ \\
Office Attendants (6 Person Years) & Offecretaries saved \\
(each 1 for one department) & (for all the six departments \\
& 3 PYs of Office Attendants saved \\
Service Delivery (6 PYs) & Service Delivery (5 PYs) \\
& 1 PY of Service Delivery staff saved \\
Marketing Communication; & Marketing Communication; Sales \& Support (12 PYs) \\
Sales \& Support (12 PYs) & 3 PYs of Marketing Communication and Sales and \\
& Support staff saved \\
\hline
\end{tabular}

\section{Conclusion}

Human resource pooling is a common strategy applied for efficient redeployment and use of resources from the available staff. The resource pooling needs to be done very carefully considering all the side effects such as, disruption, disinterest in the job, demotivation, and absenteeism. In the recent past Gamification a strategy of applying gaming and mechanics to none game context is becoming popular. The gamification can be applied for resource pooling strategy also. The behavioural change gamification and internal gamification can be helpful in resource pooling strategies. The employee behaviour change and positive attitude development using gamification techniques with rewards and badges will create wonders.

\section{Conflicts of Interest}

The authors declare no conflicts of interest regarding the publication of this paper.

\section{References}

[1] Taylor, D. (1993) Pooling Resources: A Creative Way to Reduce Costs and Improve Service.

http://www.collectionscanada.gc.ca/eppp-archive/100/201/301/tbs-sct/tb_manual-ef /Pubs_pol/opepubs/TB_D1/INNOVA5_e.html

[2] MSG (Management Study Group) (2018) Common Resource Pool Model of Human Capital Management.

https://www.managementstudyguide.com/common-resource-pool-model-of-huma n-capital-management.htm

[3] Oracle Corporation (2016) Understanding Resource Pools. https://docs.oracle.com/cd/E51433_01/fscm92pbr2/eng/fscm/frmt/concept_Unders tandingResourcePools-9f296d.html

[4] Department of Information and Communication Technology (2018) Resource Pooling Strategy. Republic of the Philippines.

http://i.gov.ph/wp-content/uploads/2017/11/Resource-Pooling-Strategy.pdf 
[5] Quelch, J.A. and Bloom, H. (2015) Ten Steps to a Global Human Resources Strategy: Creating an Effective Global Work Force Means Knowing When to Use "Expats," When to Hire "Locals" and How to Create that New Class of Employees-The "Glopats." World View, 15.

[6] Prima, K. (2002) Organizations Explore Benefits of Pooling Workers. IT World Canada.

https://www.itworldcanada.com/article/organizations-explore-benefits-of-poolingworkers/26353

[7] Coleman, F. and Winters, G. (2006) The Power of Pooling Resources. IPE. https://www.ipe.com/analysis/analysis/the-power-of-pooling-resources/18528.article

[8] Msiska, B. (2017) Pooling Human Resources Needed to Leverage Open Source Health Information Software Platforms in Developing Countries. 2017 IST-Africa Week Conference (IST-Africa), Windhoek, 30 May-2 June 2017, 1-8. https://doi.org/10.23919/ISTAFRICA.2017.8102370

[9] Oasis HR Group (2014) RTT: Part 1-Talent Pooling on Paper: Building the Business Case and Measuring ROI. HR Think Tank Series. Resourcing Think Tank.

https://oasishr.com/part-1-talent-pooling-paper-building-business-case-measuringroi/

[10] James, R. (1999) What You Need to Know About Pooling of Interests Accounting. Journal of Compensation and Benefits. https://ssrn.com/abstract=2390286

[11] Boon, C., Eckardt, R., Lepak, D.P. and Boselie, P. (2018) Integrating Strategic Human Capital and Strategic Human Resource Management. The International Journal of Human Resource Management, 29, 34-67. https://doi.org/10.1080/09585192.2017.1380063

https://er.educause.edu/articles/2017/6/expanding-your-recruitment-pool-throughincreasing-diversity-equity-and-inclusion

[12] Wanjira, F., Muathe, M. and Makau, S. (2017) Talent Management: A Conceptual Framework from Review of Literature and a Research Agenda. Journal of Human Resource Management, 5, 90-94. https://doi.org/10.11648/j.jhrm.20170506.11

[13] McIntosh, K., Pomerantz, J., Rodrigues, H., Smith, C. and Woo, M. (2017) Expanding Your Recruitment Pool through Increasing Diversity, Equity, and Inclusion. Educause. 